\title{
The Value of Scrotal Biopsy in Leprosy
}

\author{
NARENDRA J. PANDYA \\ B.Y.L. Nair Hospital and Jarlor Hospital and \\ Research Centre, Bombay, India \\ and \\ NOSHIR H. ANTIA \\ Tata Dept of Plastic Surgery, \\ J. J. Group of Hospitals, Bombay, India
}

\begin{abstract}
Forty-five scrotal skin and underlying dartos biopsies from leprosy patients of varying types, duration and treatment status were examined for quantitative bacteriology and qualitative histology. $33 \%$ on homogenization and $34 \%$ on histology were positive for acid fast bacilli. The average bacillary load/g of positive tissue was $1.5 \times 10^{7} .45 \%$ of scrotal biopsies were positive against $42 \%$ of the skin patch when examined for qualitative changes diagnostic of leprosy. These changes were more marked in the scrotal biopsies in the borderline and lepromatous types. They were chiefly restricted to the neurovascular bundles with unaffected smooth muscle. A stained smear obtained from scrotal skin homogenate is recommended for bacteriological diagnosis as a superior method than routine multiple skin smears or nasal scraping. Repeated use of scrotal biopsies is emphasized when frequent observations of neurological changes are necessary.
\end{abstract}

\section{Introduction}

Both unstriated and striated muscle have been described as favoured sites for Myco. leprae in man. Nishihura, Sirset and Khanolkar (1960) reported the finding of Myco. leprae in smooth muscle cells of blood vessels in an electron-microscopic study of leprosy lesions. Hashizume and Shionuma (1965) reported finding Myco. leprae in and between smooth muscle cells of the iris in a similar study. The erector pili and dartos have been described by Harman (1968) and Esiri (1969) to contain Myco. leprae. Rees and Weddell (1968) described the striated muscle as a privileged site of Myco. leprae in the mouse and Pearson, Rees and Weddell (1970) have demonstrated the presence of Myco. leprae in human muscle. Convit, Arvelo and Mendoza (1960), Ishihara (1959), and Job (1969) have also described leprous myositis.

All these reports emphasize the presence of Myco. leprae in the actual muscle fibres and not in the interstitial tissue between the fibres.

\section{Materials and Methods}

Scrotal skin and underlying dartos muscle was biopsied from 45 male patients who were undergoing multiple biopsies of other tissues as a part of a larger study.

* Received for publication 10 January, 1974 
Their age varied from 11 to 51 years. The duration of the disease since the appearance of the first symptoms varied from 3 months to 30 years. Five patients were untreated when first seen while 40 patients had received treatment with DDS for a period varying from one month to 30 years. These patients were studied clinically in great detail including bacteriology and were classified according to the Ridley-Jopling Scale using both clinical and histological features. (Table 1). Of the total 45 patients, 12 were tuberculoid, 22 borderline, and 11 lepromatous in type.

\section{TABLE 1}

\section{Percent positivity, by histology, and bacillary load/g of tissue, of Myco. leprae on homogenization in the various tissues examined}

\begin{tabular}{lcc}
\hline Tissue & $\begin{array}{c}\text { Positive by } \\
\text { histology }(\%)\end{array}$ & $\begin{array}{c}\text { Homogenization } \\
\text { bacillary load/g }\end{array}$ \\
\hline Nerve & 60 & $8.6 \times 10^{7}$ \\
Lymphnode & 25 & $4.4 \times 10^{7}$ \\
Nasal Mucosa & 22 & $2.0 \times 10^{7}$ \\
Scrotal Skin & 34 & $1.5 \times 10^{7}$ \\
Skin & 24 & $2.85 \times 10^{5}$ \\
Muscle & 8 & $2.6 \times 10^{5}$ \\
\hline
\end{tabular}

An ellipse of scrotal skin with underlying dartos muscle, approximately $2 \mathrm{~cm} \times$ $1 \mathrm{~cm}$ was obtained as a biopsy and divided into two equal halves, one half for homogenization and other half for histology. A manual glass homogenizer was used and bacillary count was done according to the method of Rees (1964). TRIFF (a combination of Trichrome and Fite Faraco) stain, which presents a consolidated picture showing acid fast bacilli in the tissue, was used. Similar studies were undertaken on biopsies of the skin from the most evident and active skin site, nasal mucosa, voluntary muscle, lymph node and nerve. Multiple skin and nasal smears and the sternal marrow biopsy was also obtained.

All homogenates positive for acid fast bacilli were plated on Jensen Lowenstein medium. No growth was seen in any case.

\section{Results}

Of the total of 45 scrotal biopsies, 40 were homogenized and $13(33 \%)$ showed presence of acid fast bacilli. Of all the 45 studied by histology, 15 (34\%) showed the presence of acid fast bacilli. The average bacillary load $\mathrm{g}$ of positive tissue was 1.5 $\times 10^{7}$. Histologically, scrotal skin was next only to the nerves in positivity but in terms of bacterial load it was preceded by the nerves, lymph node and nasal mucosa. Nevertheless as compared to the skin, the bacillary load was almost a hundred fold greater. (Table 2).

Table 2 shows a comparative study between the skin patch and scrotal skin according to the classification when compared in the same patients.

$45 \%$ of scrotal biopsies were positive against $42 \%$ of skin biopsies when examined for qualitative changes diagnostic of leprosy even though the skin site which was selected was a clinically involved patch while the scrotal biopsy was obtained from a clinically uninvolved area.

The histological changes were noticed more in the scrotal biopsies in the 
TABLE 2

Comparative histological study for AFB between skin patch and scrotal skin according to classification in the same patients

\begin{tabular}{lccc}
\hline Type & Total & $\begin{array}{c}\text { Skin patch (\%) } \\
\text { positive for } \\
\text { Myco. leprae }\end{array}$ & $\begin{array}{c}\text { positive for } \\
\text { Myco. leprae }\end{array}$ \\
\hline Tuberculoid & 12 & $5(40)$ & $3(25)$ \\
Borderline & 22 & $10(45)$ & $8(37)$ \\
Lepromatous & 11 & $4(37)$ & $9(82)$ \\
Total & 45 & 19 & 20 \\
\hline
\end{tabular}

lepromatous type (88\%) while skin changes were better observed in the tuberculoid type $(40 \%)$.

The advantage of scrotal skin over other skin sites for the histological detection of bacilli is confined to the lepromatous side.

Of the 11 patients showing changes both in the skin patch as well as scrotal skin, 7 showed greater changes in the scrotal biopsies, 2 in skin patch, and 2 similar changes in both tissues.

Of the 3 lepromatous patients in this group one scrotal biopsy showed greater changes than the skin patch while the other two showed changes of equal intensity. In the borderline type, all the six scrotal biopsies showed greater changes than the skin patch. In the two patients of tuberculoid type, the skin patch changes were more marked than the scrotal skin.

\section{Discussion}

Our results demonstrate the much higher rate of bacterial positivity in scrotal biopsy as compared to the routine skin and nasal smear technique or even multiple skin smear or skin biopsy (Table 3 ).

TABLE 3

Percentage of samples yielding positive findings for Myco. leprae by different procedures

\begin{tabular}{lc}
\hline Procedure & $\begin{array}{c}\% \text { positive } \\
\text { for Myco. leprae }\end{array}$ \\
\hline Routine skin patch and/or ear lobule & 12 \\
Multiple smears & 14 \\
Nasal scraping & 14 \\
Scrotal skin on homogenization & 33 \\
\hline
\end{tabular}

Another equally and probably more significant finding on histology was that in almost all cases the involvement was chiefly restricted to the neurovascular bundles. The nerves showed Schwannian proliferation and infiltrate of macrophages and lymphocytes, the nature of the infiltrate corresponding to the 
classification of the case and was the same type as seen in the skin or nerve of the same individual. The extent of the infiltrate was often more marked than seen in the most prominent skin patch. The presence of bacilli was also generally restricted to the site of the neurovascular bundles, being in the schwann cells and macrophages.

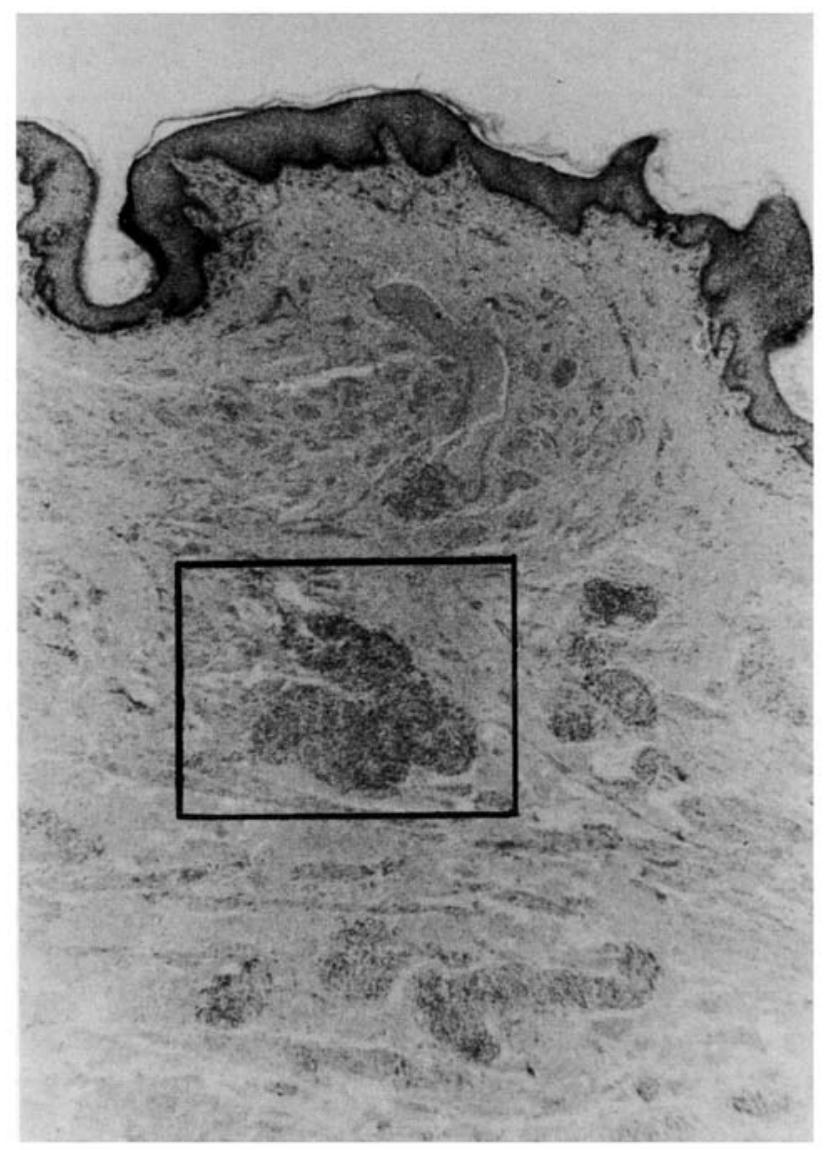

Fig. 1. Scrotal skin to show heavy cellular infiltration of the neurovascular bundles throughout the field.

Another remarkable feature was the absence of infiltrate and bacilli in relation to the smooth muscle fibre and bundles of the dartos. Infiltration of the dartos (true myositis) was seen only in 4 cases and even here it was of minimal nature as compared to the involvement of the neurovascular bundles. Myco. leprae were observed in the smooth muscles in 3 biopsies. These were solid and well preserved, the muscle architecture being normal in spite of their presence.

These histological and bacteriological results were observed even though none of these cases showed any evidence of clinical involvement of the scrotal skin.

In fact the presence of bacilli in lepromatous cases probably emphasises that 


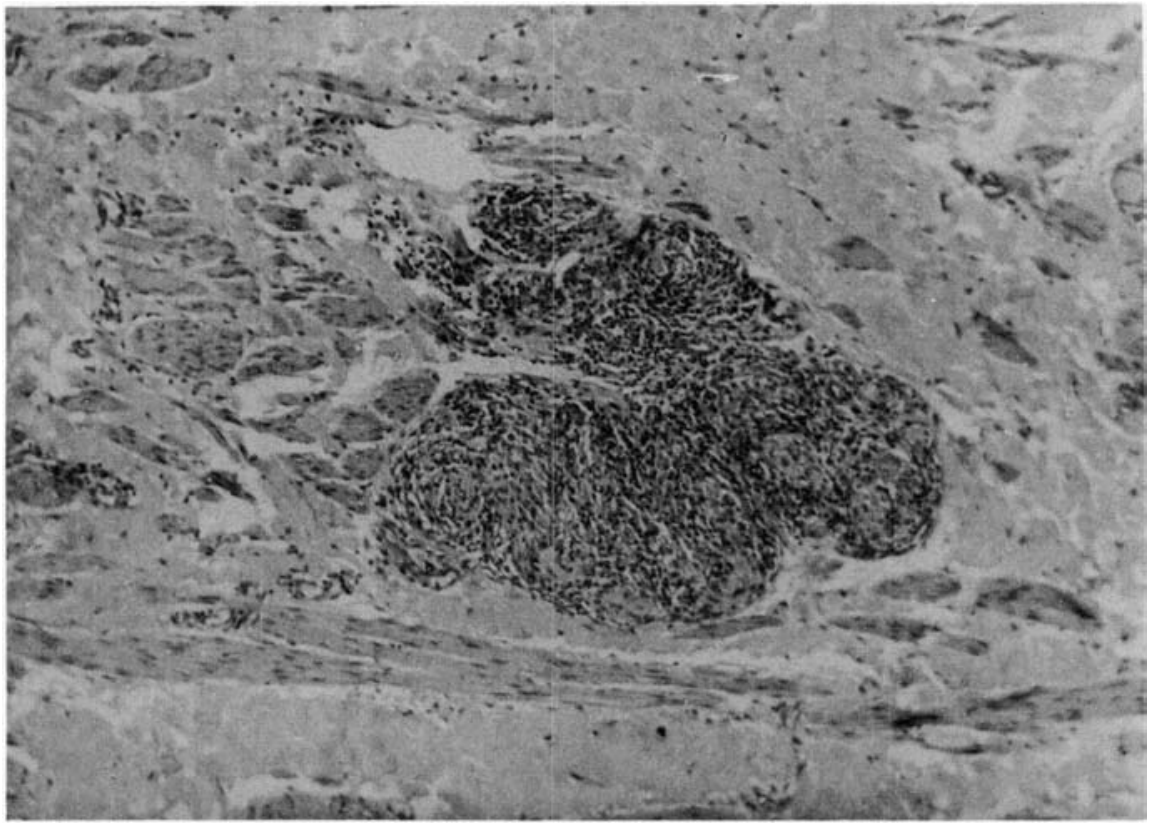

Fig. 2. Magnified view of the nerve in Fig. 1 to show the heavy cellular infiltrate. Note the normal muscle architecture.

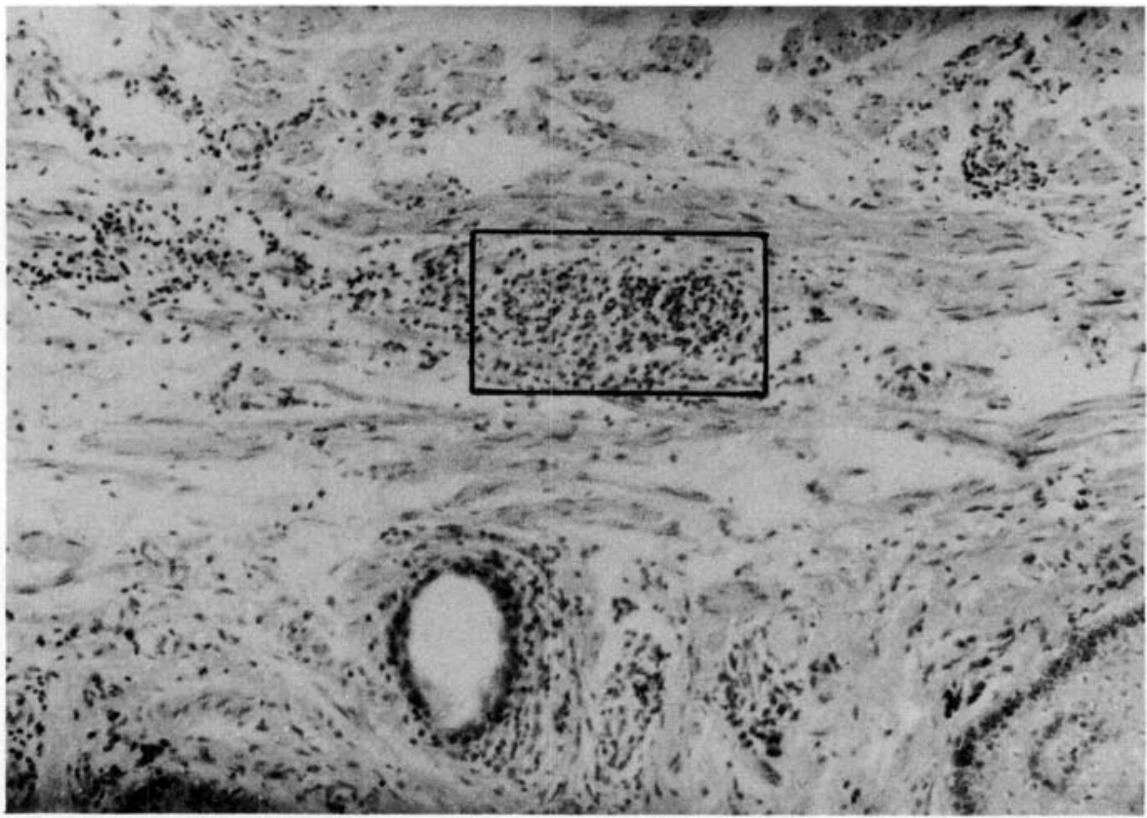

Fig. 3. Intermuscular cellular infiltration. 


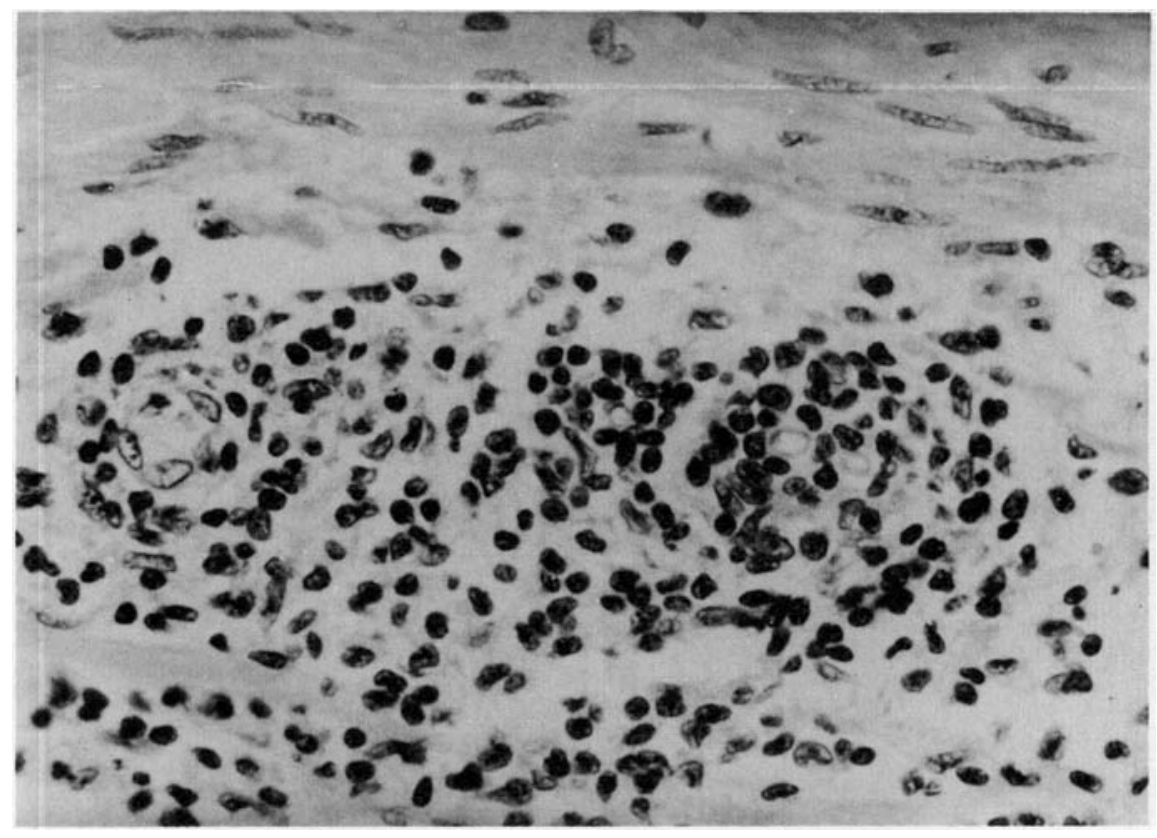

Fig. 4. Magnified view of the area seen in Fig. 3. Note the normal muscle fibres.

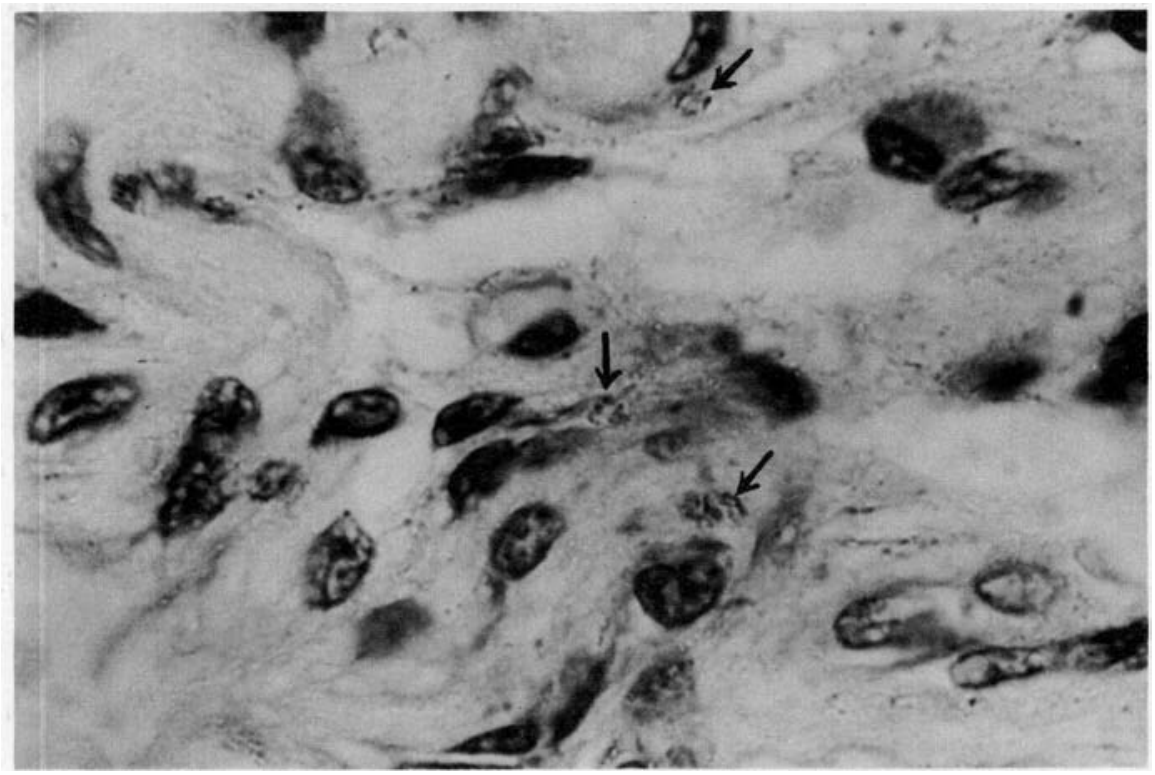

Fig. 5. Mycobacterium leprae in the Schwann cells of the nerves in the scrotal skin. 


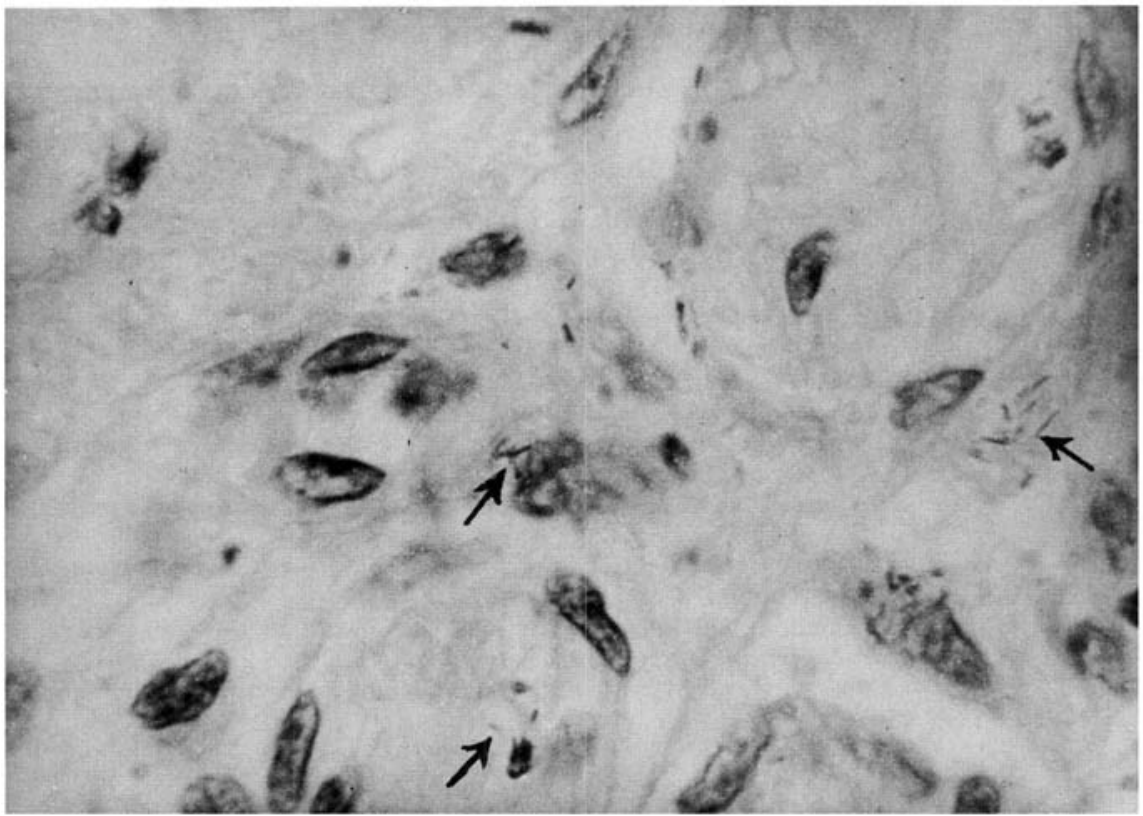

Fig. 6. Mycobacterium leprae in the scrotal muscle fibres in the same patient. Note the relatively better preserved bacilli.

scrotal biopsy will provide evidence of bacillation in long standing leprosy even where the skin may be negative bacteriologically. This may be because scrotal biopsy gives a better sampling of nerves than skin biopsy.

Since the larger nerves are in the deeper part of the dartos muscle, the depth of biopsy is considered important. After incising the skin, the pink muscle should be grasped by a toothed forceps, pulled out of the wound and excised with sharp scissors. One or two deep sutures help to close the wound and produce hemostasis. The resulting scar is unnoticeable.

The scrotal skin is more liberally supplied with nerves and these are larger than other cutaneous nerves. Presence of these nerves and a virtually unnoticeable scar, makes this site a suitable source for repeated observations of neurological changes, as in cases where the response to treatment may need to be studied at intervals.

Quantitative bacteriology by homogenization and qualitative histology gave similar findings for the presence of acid fast bacilli. Wherever histology facilities are not available, the presence of acid fast bacilli can be ascertained by the examination of a stained smear obtained from the homogenate. This would prove to be a superior method of bacteriological diagnosis than multiple skin smears or nasal scraping and could be particularly useful in field studies in the developing countries.

The nerves in scrotal skin showed definite changes in those patients especially with primary neuritis. This would indicate that the involvement of these nerves is a part of a generalized diffuse peripheral neuropathy. 


\section{Acknowledgement}

We wish to thank The Wellcome Trust, London, for the support to conduct this study.

\section{References}

Convit, J., Arvelo, J. J. and Mendoza, S. (1960). Lepromatous myositis. Int. J. Lepr. 28, 417. Esiri, M. M. (1969). Studies of Intramuscular Leprosy Bacilli B.Sc. Thesis, University of Oxford.

Harman, D. J. (1968). Mycobacterium leprae in muscle. Lepr. Rev. 39, 197.

Hashizume, H. and Shionuma, E. (1965). Electron microscopic study of lepromatous changes in the iris. Int. J. Lepr. 27, 61.

Ishihara, S. (1959). A study of myositis interstitialis leprosa. Int. J. Lepr. 27, 341.

Job, C. K., Karat, A. B. A., Karat, S. and Mathan, M. (1969). Leprous myositis - an histopathological and electron-microscopic study. Lepr. Rev. 40, 9.

Nishihura, M., Sirsat, S. M. and Khanolkar, V. R. (1960). Electron microscopic study of leprosy lesion. Leprosy in India 32, 90.

Pearson, J. M. H., Rees, R. J. W. and Weddell, A. G. M. (1970). Mycobacterium leprae in the striated muscle of patients with leprosy. Lepr. Rev. 41, 155.

Rees, R. J. W. (1964). Limited multiplication of acid fast bacilli in the footpads of mice inoculated with Mycobacterium leprae. Brit. J. exp. Path. 45, 207.

Rees, R. J. W. and Weddell, A. G. M. (1968). Experimental models for studying leprosy. Ann. N.Y. Acad. Sci, 154, 214. 